\title{
Framework for Articulating Relation between Teachers' Practices and Students' Self-efficacy in Teaching and Learning Euclidian Geometry in High School
}

\author{
Dikeledi Mamiala ${ }^{1}$, Sibongile Simelane-Mnisi ${ }^{2}$, Andile $\mathbf{M j i}^{3}$ \\ ${ }^{1}$ Department of Mathematics, Science \& Business Education, Faculty of Humanities, \\ Tshwane University of Technology, Pretoria, South Africa \\ ${ }^{2}$ Higher Education Development \& Support, Department of Curriculum Development \& Support: ELearning, \\ Tshwane University of Technology, Pretoria, South Africa \\ ${ }^{3}$ Faculty of Humanities, Tshwane University of Technology, Pretoria, South Africa
}

Received August 9, 2021; Revised November 20, 2021; Accepted December 13, 2021

\section{Cite This Paper in the following Citation Styles}

(a): [1] Dikeledi Mamiala, Sibongile Simelane-Mnisi, Andile Mji, "Framework for Articulating Relation between Teachers' Practices and Students' Self-efficacy in Teaching and Learning Euclidian Geometry in High School," Universal Journal of Educational Research, Vol. 10, No. 1, pp. 22 - 35, 2022. DOI: 10.13189/ujer.2022.100103.

(b): Dikeledi Mamiala, Sibongile Simelane-Mnisi, Andile Mji (2022). Framework for Articulating Relation between Teachers' Practices and Students' Self-efficacy in Teaching and Learning Euclidian Geometry in High School. Universal Journal of Educational Research, 10(1), 22 - 35. DOI: 10.13189/ujer.2022.100103.

Copyright $\bigcirc 2022$ by authors, all rights reserved. Authors agree that this article remains permanently open access under the terms of the Creative Commons Attribution License 4.0 International License

\begin{abstract}
The aim of this paper is to explore a framework for articulating the relationship between teachers' practices and students' self-efficacy in teaching and learning of Euclidean Geometry (RTP\&SS-EG) in high school. The effective learning of Mathematics, especially Euclidean Geometry by students, is directly influenced by teachers' confidence and competence. The RTP\&SS-EG framework was developed based on the gap in literature revealed through international studies, indicating a direct relationship between teachers with a higher level of self-efficacy, and students' achievement. However, the researchers did not come across national studies promoting the relationship between the teachers' practices and students' self-efficacy on the learning of Euclidean Geometry in high school. The question asked was: To what extent is the relationship between the teachers' practices and the students' self-efficacy in teaching and learning of Euclidean Geometry in High school? Geometry Students Self-Efficacy (SGS-EQ) and Geometry Teacher Self-Efficacy questionnaire (GTS-EQ) were utilized. The participants were 81 Mathematics teachers, and 390 Grade 10-12 students from the Mpumalanga and North West provinces in South Africa. Reliability for the entire scale of both instruments computed in terms of the internal consistency was found to
\end{abstract}

be .83 . To establish the content validity of the scores from both instruments, the exploratory factor analysis was computed using varimax rotation. The four-factor solution accounting for $43.03 \%$ of the total variance was obtained from 36 items of the GTS-EQ. A five-factor solution for $45.37 \%$ of the total explained variance was obtained from the 46 items of the SGS-EQ. In RTP\&SS-EG, three education theories, constructivism, social constructivism and social cognitivism, policies, as well as teacher and student self-efficacy principles enjoin the practice enacted from the relation between the teachers' practices and the students' self-efficacy in the learning of Euclidean Geometry. The findings revealed that the learning value associated with the relationship between teachers' practices and students' self-efficacy may be integrated into the everyday preparations of teaching-learning plans in Euclidean Geometry. It is critical that policymakers, curriculum developers, teachers and students make use of this model to ensure that self-efficacy of both teachers and students is taken into consideration in Euclidean Geometry.

Keywords Teacher Practices, Leaner Self-efficacy, Framework, Relation, Euclidian Geometry, High School 


\section{Introduction}

Geometry, according to [1], is the cornerstone of engineering and technical development. Between 1998 and 2007, Geometry was included in both the mathematics curriculum and the exam paper 2 in South Africa [2]. Geometry accounts for approximately 30\% of the final National Curriculum Statement Grade 12 paper [1]. According to research, Geometry has been perceived as a difficult section of the exam, as it has been directly linked to students' low performance in Mathematics [3]. For this reason, Euclidean Geometry was made an optional component of the Mathematics syllabus and examination. As a result of this action, the majority of Mathematics teachers abandoned this area during their classroom teaching, and subsequently, students interested in studying Engineering and related courses at University were denied admission due to the omittance of this important section. Due to reasons as earlier stated, some teachers were not trained in Geometry while they were student teachers. Ascribed to the challenges related to the omission of Euclidean Geometry, the subject was reinstated in the Curriculum Assessment Policy Statements in 2012 at Grade 10 in the Further Education and Training phase. In 2014, Euclidean Geometry formed part of the Grade 12 examination [4]. It is worth emphasizing the importance of Euclidean Geometry in teaching and learning, as it provides students the ability to solve problems, think critically and make use of higher-level thinking skills [3].

South Africa is regarded as underperforming in education, especially in Mathematics teaching and learning. The predominant reason for this underperformance can be attributed to the prevailing belief that Mathematics is a difficult subject to teach and learn. Literature revealed that students find Geometry difficult and challenging [5]. Furthermore, in the 21st century, it is expected that schools prepare students for the Fourth Industrial Revolution, for Education 4.0 to be relevant, and to be able to operate in the technological economy [6]. Although Geometry is viewed as critical in enhancing a high level of thinking skills, most South African schools experience challenges related to the integration of technology within a teaching and learning environment. The challenge in teaching Geometry is linked to how teacher knowledge supports effective Mathematics teaching [1]. The teaching of Geometry should constantly be innovated by introducing new methodical solutions [6]. Inquiry-based learning methods assist teachers in moving away from teacher-based teaching, or more traditional methods of teaching. In the teaching of Geometry, problem-based learning is another method that contributes to better students' performance [6]. The combination of 1986 Van Hiele's framework, as well as Bloom's taxonomy, is observed as a partial solution in the teaching of Geometry [1]. It is critical for teachers to implement innovative teaching methods as identified in this study. It may be argued that, in learning Euclidean Geometry, the Van Hiele theory-based approach appears to suit students' needs better than traditional approaches. It was reported that students with high self-efficacy obtained good achievements at level 0 (visualization) and level 1 (analysis), in understanding the elements of the prism [7]. By contrast, students with low self-efficacy do not understand the elements of the prism.

Teacher practices within a teaching-learning environment have an impact on teaching and learning outcomes $[8,9,10,11]$. Therefore, the establishment of students' outcomes is the first step that needs to be taken in consideration of the learning process efficacy [12]. This implies that a structured teaching plan with clearly defined outcomes should be coherent to the students [13]. It is only through such teaching plans where students understand the objectives of teaching activities, that they are then able to achieve such objectives. The researchers, as Mathematics teachers, argue that Geometry enhances students' reasoning, and encourages logical thinking in their assessment of situations or ideas. The reasoning is to use Geometry as well as mathematical knowledge to generate and solidify ideas that are new to us. Through reasoning, students develop their own sense of Geometry and mathematical coherence of the things they are learning.

The purpose of this study was to investigate the framework for articulating the relationship between teachers' practices and students' self-efficacy in the teaching and learning of Euclidean Geometry (RTP\&SS-EG) in high school. To develop a RTP\&SS-EG framework, Geometry Students Self-Efficacy (SGS-EQ) and Geometry Teacher Self-Efficacy questionnaire (GTS-EQ) were utilized. The framework was developed based on the findings from this study conducted by [11], and the gap in literature that shows that international studies researched teachers' practice in Mathematics teaching [14]. The RTP\&SS-EG framework at the school level in the South African context, is a contribution to the body of knowledge. There were limited studies in South Africa that investigated this phenomenon. Previous studies examined teachers' practices and students' perceptions as separate entities [15]. International studies revealed that there is a direct relationship between teachers with a higher level of self-efficacy, and students' achievement [16]. The researcher did not come across national studies promoting the relationship between the teachers' practices and students' self-efficacy on the learning of Euclidean Geometry in high school.

This study commences with the discussion of the theoretical framework focusing on constructivism, social constructivism, social cognitive, self-efficacy, teachers' self-efficacy, and students' self-efficacy. This is followed by the presentation of material and methods. Furthermore, the presentation of the results and discussion of the 
findings are addressed. Finally, the conclusion and the recommendation are provided.

\section{Theoretical Framework}

In this study, three theories postulate the rationale for the investigation of the relationship between teacher practices and students' views on the teaching and learning of Euclidean Geometry at the Further Education and Training (FET) phase. These theories include constructivism and social constructivism (Piaget and Vygotsky), social cognitive theory [17] as well as the theory of self-efficacy [18].

\subsection{Constructivism}

The theory of constructivism maintains that meaning is constructed in our minds as we interact with the physical, social, and mental world [19]. Constructivism is described as an approach in which students share the responsibility for their learning, while negotiating meaning through active participation in the co-creation of shared understanding within the learning context [20]. A constructivist perspective regards active learning as a process that is present in a teaching and learning situation, associated with the existing individual experiences of students about their world [21]. The emphasis on the application of mathematical skills may also be assigned to the theory of constructivism. Constructivism transforms how teaching and learning are viewed in Mathematics, especially with its abstract nature in some of the concepts present in Euclidean Geometry. Constructivists may make sense of the relationship between teacher practices and students' self-efficacy in the teaching and learning of Euclidean Geometry in high school. Teaching and learning of Geometry, therefore, stand in need of students to demonstrate an in-depth understanding of Geometry concepts, and provide a continuous indication of their conceptual understanding and construction of new information on their own.

\subsection{Social Constructivism}

Within the context of social constructivism, perspective learning is viewed to be directly linked to the interactions between teachers, learners, and the activity being done [22]. From a social constructivism perspective, mathematical language plays a crucial role in the learning process in order to facilitate students' cognitive development, as both the teacher and students collaborate in developing students' skills and understanding to solve real-life problems [23]. Learning is the apprenticeship process wherein students, through the guidance from teachers and their peers, can work on authentic problems [24]. The teacher is required to create a conducive learning environment where students could be motivated to participate, think, and act within the context of real-life tasks - like an apprentice. Teachers should scaffold learning within students. Social constructivist learning provides an appropriate theoretical framework for teacher practices and student self-efficacy in teaching and learning. In these perspectives, teacher practices and students' self-efficacy are viewed as an active social process that is attained through the quality of teacher-student interactions within a teaching-learning environment [25]. Thus, it informs that the relationship between teacher practices and students' self-efficacy may be regarded as a collaborative process between teachers and students, rather than it being dependent on an individual mind $[12,13]$.

\subsection{Social Cognitive}

In social cognitive theory, learning is described as developmental active and reflective engagement, where mental construction is connected to activities within the environment [19]. Students make sense through their prior knowledge (Schema) and accommodate such knowledge into the new information [26]. The focus of the cognitive approach is on what is taking place in the student's mind rather than just viewing learning as a stimulus-response. The students are viewed as an active participant in the learning process, which should be emphasized in the learning of Euclidean Geometry.

The central point of the social cognitive theory within the context of teacher practices and students' self-efficacy in the teaching and learning of Euclidean Geometry, is that teaching is a way of knowing what students know, as well as how and when they use the knowledge to solve Geometry problems [27]. Teachers' reflection on their practice is not just a tool they use in Geometry teaching, as it is also a method of gathering and interpreting information during teaching with the ultimate aim to improve learning. Unlike the traditional paper and pencil teaching and learning methods, which may provide information only on a certain aspect of learning, teachers need to make use of alternative teaching and learning strategies in Mathematics, especially Geometry. High order thinking in Mathematics, the inclusion of procedural knowledge to solve Geometry related problems, as well as the application of such information to real-life problems is enhanced through the implementation of alternative approaches to teaching [25].

\subsection{Self-efficacy}

Self-efficacy beliefs are defined as people's judgements of their capabilities to organize and execute courses of action required in attaining designated types of performances [18], while [28] defines it as people's confidence in their ability to do the things they try to do. In this study, self-efficacy is defined - within the 
Geometry context - as teachers' and students' judgement of their own capabilities to organize and perform Geometry activities required in achieving relevant types of performances. The basic principle behind self-efficacy is that teachers and students are more likely to engage in activities for which they have high self-efficacy and are less likely to engage in those they do not [29]. In this case, Geometry activities and exercises must be designed in a manner that would foster engagement and participation to create high self-efficacy among teachers and students. The self-efficacy frameworks provide the foundation for teacher or student motivation, well-being, and personal accomplishment. Their actions are based more on what they believe than on what is objectively true. Furthermore, teachers and students are more likely to be involved in activities for which they have high self-efficacy, and less likely to be involved in those they do not.

\subsection{Teachers' Self-efficacy}

Teachers' self-efficacy includes four components, which are viewed as the pillars of the constructivist teaching approach to Geometry [30]. These components relate to teachers' competency, engagement, flexibility, and teacher competency relative to other teachers.

\subsubsection{Teacher competency}

Pedagogical competences may be viewed as an indicator of the quality of teachers, and as such, it must be given special attention within the context of teaching and learning of Euclidean Geometry at school level [31]. For Mathematics teachers to be competent in teaching Mathematics, they need to constantly consider professional learning as a means to address some of the concerns raised with regard to imited knowledge of Euclidean Geometry.

\subsubsection{Teacher engagement}

Engagement of students in a learning situation may be viewed as a function of how the teacher engages during the teaching and learning of Geometry [11]. It was found that the development of learning materials that are based on the Realistic Mathematics Education (RME) approach, contributes to promoting students' engagement in problem-solving activities, thereby increasing self-confidence and self-efficacy $[32,33]$. In this regard, creative thinking during teaching and learning situations, especially in Geometry, was promoted.

\subsubsection{Teacher flexibility}

Flexibility suggests a teacher is able to display the ability to adopt various teaching strategies that may enhance Mathematics teaching [30]. It is regarded as the teacher's capability to be flexible during Mathematics teaching. The development of learning materials perpetuating a cultural context may also contribute towards promoting flexibility [34]. Part of the efforts that may contribute towards promoting cultural inclusive approaches, may be those that recognize the value of parental involvement [35]. It is critical that in South Africa, Geometry teachers also include indigenous or local geometrical examples in teaching and learning.

\subsubsection{Teacher competency relative to other teachers}

Teachers' competence relative to other Mathematics teachers is the comparison of teachers with their peers [30]. The significant finding in this aspect is how the teachers view themselves to be better, compared to other teachers. Mathematical disposition and self-efficacy for teaching Mathematics are viewed as critical aspects contributing to teachers' beliefs and impact on practices in teaching and learning [36]. In this case, it was indicated that mathematical disposition may be viewed as a predictor of self-efficacy for teaching Mathematics. Therefore, mathematical disposition and self-efficacy for teaching Mathematics, in turn, were influenced by the teachers' prior Mathematics teachers [37].

\subsection{Students' Self-efficacy}

Students' self-efficacy consists of five components: students' competency in Geometry, students' Geometry anxiety, how comfortable a student feels with Geometry, students' interest in Geometry, and the importance of Geometry to the student [30].

\subsubsection{Student competence in Geometry}

Students' overall attitudes towards Geometry influence their efficacy in learning the subject. It may be argued that the skill of a teacher to enhance a student's ability to apply mathematical knowledge into real life is critical in promoting student competency. A range of factors that contributed to students' competency in Mathematics include learning beliefs, enjoyment in the subject, a positive desire to help one another as well as to improve their Mathematics learning 38]. These competencies may also be attributed to Geometry.

\subsubsection{Students' Geometry anxiety}

In schools, anxiety has been demonstrated to have a negative impact on a student's capacity to gain a conceptual understanding of Mathematics. [39]. Anxiety in Geometry can also lead to low self-efficacy in students, as poor performance causes them to feel uneasy and avoid Math [9]. Anxiety over performing in Geometry is characterized by feelings of tension, nervousness, and fear. Students become less competent in Geometry as a result of their fear, and they develop a negative attitude toward the subject [40].

\subsubsection{Comfort student feels about Geometry - how at ease}

The comfort a student feels about Geometry is 
influenced by the mastery experience, vicarious experience, and verbal persuasion [6]. In mastery experience, students' direct experiences help in the successful performance of geometric tasks, which reinforces optimistic self-efficacy perceptions. The vicarious experience involves self-efficacy when students are observed performing challenging tasks such as proving geometric theorems. The approach and technique that students use to overcome this challenging vicarious experience, allows for the development of optimistic perceptions. Verbal persuasions during motivational discussions involve teachers who are skillful persuaders, who focus on an individual's skills, therefor counter-acting doubt and obsession with personal shortcomings and weaknesses among students. These motivational discussions convince students to focus more on skills that will assist them to be successful [41]. It is necessary for the teacher to ensure that students are comfortable within the learning environment.

\subsubsection{Student interest in Geometry}

Students' self-efficacy in learning Geometry is boosted by their interest [30]. Student engagement, teacher flexibility, and assignment frequency all favorably enhance students' interest in the subject [7]. Motivation encourages students' interest in Geometry. One of the important elements discovered to be closely associated to interest was motivation. As a result, it is critical to concentrate on how it links to and improves self-efficacy in Geometry [32].

\subsubsection{The importance of Geometry to the students}

Students' perceptions of the importance of Geometry are viewed as a predictor of their success [30]. Students' views on the importance of Geometry, from this context, is one of the aspects that the current study intends to establish; how such links apply to the South African schools situated within mainly disadvantaged communities. The importance of Geometry is also linked with the students' development of mental processes regarded as pivotal in enhancing logical and critical thinking for problem-solving, contributing to decision-making [4]. Geometry problem-solving activities within the mathematics curriculum is viewed as important in aiding students to understand the world (physical, social, and economic) around them, while enhancing creativity and innovative thinking [42].

\section{Materials and Methods}

\subsection{Research Question}

The question asked was: To what extent is the relationship between the teachers' practices and the students' self-efficacy in teaching and learning of Euclidean Geometry in High school? To answer this question, the SGS-EQ and GTS-EQ were utilized. These instruments were adapted from [30]. SPSS was utilized to determine the reliability and the validity of the instruments.

\subsection{Participants}

The participants were 81 Mathematics teachers and 390 Grade 10-12 students from Mpumalanga and North West in South Africa. Homogeneous sampling was used to identify participants. Homogeneous sampling is a type of method in which groups and individuals are chosen based on similar or unique features [43]. In this study, the similarity may be described in terms of teachers and students involved with Mathematics in high school. Approximately $61.7 \%$ of the teachers were men. Approximately $70.3 \%$ of the teachers were over 40 years of age, $23.5 \%$ were between the ages $30-39$, and $6.2 \%$ were between the ages 20-29. Table 1 is a cross-tabulation of the students' biographical information by age, gender, and parents. All participating students disclosed their biographical data. The results show that the students consist of 154 males and 236 females. Of these students, 143 female and 90 male students were between 18-19 years. With regard to parents, it may be seen from the results that 199 students had both parents, and 191 had single-parent homes or no parent. Of these students whose age ranged from 18-19 years, 114 had both parents, and 119 had single-parent homes or no parent.

\subsection{Instruments and Procedure}

Two instruments, GTS-EQ and GSS-EQ were used in this study. The GTS-EQ consisted of 36 items and four constructs. The constructs related to (a) Teacher competency; (b) Teacher Engagement; (c) Teacher Flexibility; and (d) Teacher Competency Relative to other Teachers. The participants had to use a rating system - the 4-point Likert scale. The scale had the following options: $1=$ Strongly Disagree, $2=$ Disagree, $3=$ Agree, and $4=$ Strongly Agree. The GSS-EQ consisted of 38 items with five constructs. The constructs related to (a) How competent a student feels about Geometry; (b) How anxious a student is about Geometry; (c) How interested a student is in Geometry; (d) The importance of Geometry to a student; and (e) How comfortable or at ease a student is with Geometry. The scale had the following options: 1 $=$ Definitely False, 2 = False, $3=$ More False than True, 4

$=$ More True than False, $5=$ True and Definitely True.

To establish the content validity of the scores from both instruments, the exploratory factor analysis was computed using varimax rotation. The four-factor solution accounting for $43.03 \%$ of the total variance was obtained from 36 items of the GTS-EQ. A five-factor solution for $45.37 \%$ of the total explained variance was obtained from the 46 items of the SGS-EQ. 
Table 2 shows the number of items, means, standard deviations and alpha values for the GTS-EQ constructs. Reliability for the entire scale computed in terms of the internal consistency was found to be .83 . In terms of the four construct of the GTS-EQ - the internal consistency alpha values ranged between .70 and .84 . The alpha values were adjudged to be fair to good, based on the guidelines for clinical significance of fair if .70 $\leq \alpha<.80$; good if $.80 \leq \alpha<.90$; and $\geq .90$ excellent [44]

Table 3 shows the number of items, means, standard deviations and alpha values for each SGS-EQ construct. The internal consistency alpha value for the entire scale was found to be good. The table shows that the alpha values of the different constructs were found to be fair to good.

\section{Results and Discussion}

The results are presented according to Figure 1, the framework for articulating the relationship between the teachers' practices and the students' self-efficacy in learning of Euclidean Geometry (RTP\&SS-EG) in high school as the contribution to the body of knowledge [11]. The RTP\&SS-EG framework could guide the mathematics practice particular to the teaching and learning of Euclidean Geometry, both in high school and similar contexts. The RTP\&SS-EG framework assisted the researchers to respond to the research question: To what extent is the relationship between the teachers' practices and the students' self-efficacy in teaching and learning of Euclidean Geometry in high school? This framework could also guide policymakers, curriculum developers, and mathematics teachers in articulating the relationship between the teachers' practices and the students' self-efficacy in learning Euclidean Geometry within the high school context. Learning value associated with the relationship between teachers' practices and students' self-efficacy may be integrated into the everyday preparations of teaching-learning plans in Euclidean Geometry. New dimensions to the theory and subsequent practice on the integration during the teaching and learning of Euclidean Geometry, may be incorporated with the guidance of this framework.

\section{Framework for articulating relation between the teachers' practices and the students' self-efficacy in learning of Euclidean Geometry at the school level}

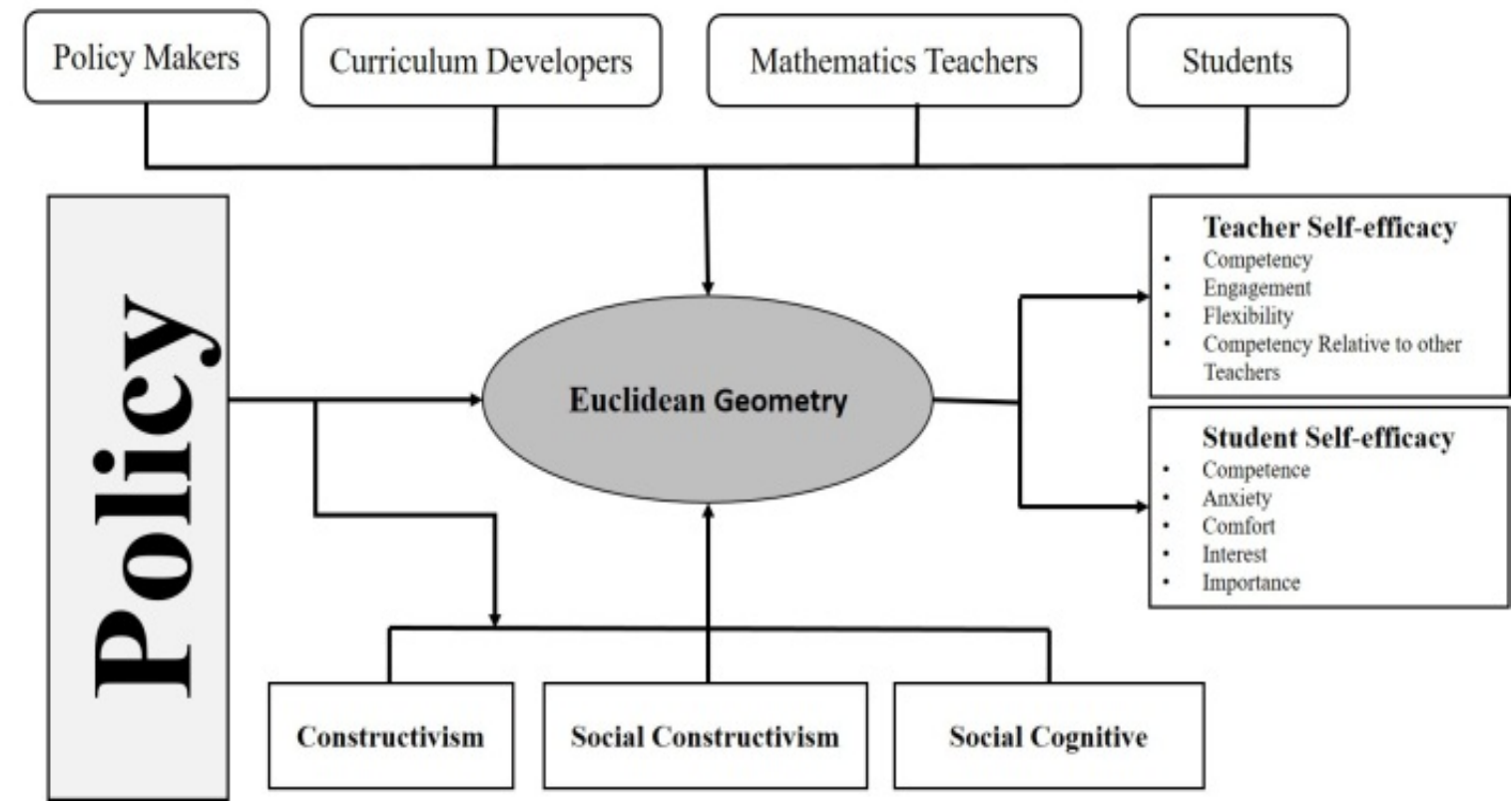

Figure 1. The framework for articulating relation between the teachers' practices and the students' self-efficacy in learning of Euclidean Geometry in high school 
Table 1. Student's biographical data

\begin{tabular}{|c|c|c|c|c|c|}
\hline \multicolumn{6}{|c|}{ Age } \\
\hline & & $\begin{array}{c}15-17 \\
\text { years }\end{array}$ & $\begin{array}{c}18-19 \\
\text { years }\end{array}$ & $\begin{array}{c}20 \\
\text { years or } \\
\text { more }\end{array}$ & Total \\
\hline \multirow[t]{2}{*}{ Gender } & Male & 35 & 90 & 29 & 154 \\
\hline & Female & 74 & 143 & 19 & 236 \\
\hline \multicolumn{2}{|c|}{ Total } & 109 & 233 & 48 & 390 \\
\hline \multirow[t]{2}{*}{ Parents } & $\begin{array}{c}\text { Single or } \\
\text { No Parent }\end{array}$ & 46 & 119 & 26 & 191 \\
\hline & $\begin{array}{c}\text { Both } \\
\text { Parents }\end{array}$ & 63 & 114 & 22 & 199 \\
\hline \multicolumn{2}{|c|}{ Total } & 109 & 233 & 48 & 390 \\
\hline
\end{tabular}

Table 2. Number of items, means, standard deviations and alpha values for the GTS-EQ constructs

\begin{tabular}{|c|c|c|c|c|}
\hline Construct & $\mathbf{N}$ & $\boldsymbol{M}$ & $\boldsymbol{S D}$ & $\mathbf{A}$ \\
\hline Teacher Competency & 12 & 3.10 & .11 & .84 \\
\hline $\begin{array}{c}\text { Teacher Competence Relative } \\
\text { to other Teachers }\end{array}$ & 5 & 2.83 & .15 & .70 \\
\hline Teacher Engagement & 9 & 3.09 & .27 & .75 \\
\hline Teacher Flexibility & 9 & 2.00 & .93 & .73 \\
\hline
\end{tabular}

Table 3. Number of items, means, standard deviations and alpha values for the SGS-EQ constructs

\begin{tabular}{|c|c|c|c|c|}
\hline Construct & $\mathbf{N}$ & $\boldsymbol{M}$ & $\mathbf{S D}$ & $\mathbf{A}$ \\
\hline $\begin{array}{c}\text { How competent a student } \\
\text { feels about Geometry }\end{array}$ & 11 & 3.21 & .47 & .90 \\
\hline $\begin{array}{c}\text { How anxious a student is } \\
\text { about Geometry }\end{array}$ & 14 & 3.34 & .81 & .84 \\
\hline $\begin{array}{c}\text { How interested a student is in } \\
\text { Geometry }\end{array}$ & 10 & 3.40 & .31 & .81 \\
\hline $\begin{array}{c}\text { The importance of Geometry } \\
\text { to a student }\end{array}$ & 5 & 3.93 & .14 & .74 \\
\hline $\begin{array}{c}\text { How comfortable or at ease a } \\
\text { student is with Geometry }\end{array}$ & 7 & 2.60 & .32 & .85 \\
\hline
\end{tabular}

\subsection{Stakeholders}

For the relation between the teachers and the students in teaching and learning of Euclidean Geometry to be realized, there is a need for collective commitment from all stakeholders. The main stakeholders in this process include policymakers, curriculum developers, teachers, subject specialist, and students. This framework emphasizes the value of Mathematics teachers and students' relationships as they engage in the improvement of Euclidean Geometry. If a positive relationship is established between the two parties, there is more likelihood for the students to perform and succeed in this concept. Establishment of the relationship, as well as close connection, requires radical changes in terms of teachers' practices and students' learning to be fully integrated and enhance learning. This will increase the pass and success rate of Euclidean Geometry among the students.

Professional development programs (PDP) on the teaching and learning of Euclidean Geometry may be effective if stakeholders have full knowledge as to what teachers are currently doing well, and a clear understanding as to what may be lacking, in order to establish a suitable approach towards creating a capacity development program on specific concepts. The empowerment of teachers would offer them the opportunity to be exposed to alternative modes of assessment that would encourage teachers to incorporate such modes as part of their everyday teaching at all phases so as to maintain the quality of learning and improve performance [45]. It is therefore imperative that professional learning address the limited Euclidean Geometry knowledge concern among teachers, as it influences their pedagogical approaches. Using the framework formulated in this study might assist the stakeholders to improve the quality of Euclidean Geometry teaching, and efficacy for learning could be achieved.

\subsection{Constructivism}

To maintain its value in teaching and learning of Mathematics, as well as the Euclidean Geometry concept, the theory of constructivism was suitable for inclusion in the framework as a means to articulate the relationship between teachers' practices, and students' self-efficacy on learning Euclidean Geometry. Its inclusion is on the basis that constructivism is an approach that bestows insights into the manner in which students actively share the responsibility for their learning, while exchanging meaning through engagement and collaborative-shared understanding within the learning context [20]. Teachers must consider the existing experiences of students on the knowledge they possess in the teaching and learning environment, rather than seeing them as an empty vessel. Constructivism within the framework emphasizes the application of mathematical skills for students to find meaning in the learning process and improve Mathematics education. Constructivism can transform how teaching and learning are viewed in Mathematics, especially with its abstract nature of the Euclidean Geometry concept.

In this theory, for the effective teaching of Euclidean Geometry, knowledge of content and pedagogy is not sufficient on its own [46] Knowledge of students and their characteristics are other vital aspects of the relationship. Students need to be presented with problems, whereafter teachers should fulfill their role as facilitators in an inductive inquiry process, starting with specific information and continuing with steps toward discovery [47]. In this process, the students focus on learning. This means that, during the constructivist teaching of Euclidean Geometry, reflective and pedagogic practices become part of the teachers' approach. It is through the constructivist approach that students' prior knowledge is triggered and activated. For students to benefit from conceptual understanding and problem-solving skills, they should be 
involved in meaningful dialogue, open-ended tasks and questioning [48]. Constructivism promotes student-centeredness, and a knowledge-centered approach to the teaching and learning of Euclidean Geometry as a whole.

\subsection{Social Constructivism}

The RTP\&SS-EG framework provides awareness from a social constructivist perspective. Social constructivism sees learning as a function of the interaction of students, teachers, and the tasks. This implies that students' knowledge is shaped by the community of practice, including policymakers, curriculum developers' subject expertise, and the community. Students may be able to acquire the personal meaning of learning that happens and come up with alternative solutions to solving real-life problems, particularly in the Euclidean Geometry context.

Social constructivism emphasizes an apprenticeship process in learning. During the apprenticeship process, students are guided by teachers and peers, which enables them to work on authentic problems [24]. This is the Zone of Proximal Development (ZPD) [26]. In this case, a teacher's responsibility is to scaffold learning in students in order for them to realize their independent performance, and their performance in collaboration with others. In this study, teachers' practices and students' self-efficacy are viewed as an active social process attained through the quality of teacher-student interactions within the teaching-learning context [49]. It is highlighted that the relationship between teachers' practices and students' self-efficacy is a collaborative process, rather than being dependent on an individual mind [13].

\subsection{Social Cognitive}

The social cognitive theory also contributes to the RTP\&SS-EG framework, since the cognitive approach focuses on what is taking place within the students' mind, as opposed to viewing learning as a stimulus-response. Students make sense through their prior knowledge and accommodate their prior knowledge in the new information [26]. In social cognitive theory, learning is viewed as developmental, active, and reflective engagement, where mental construction is connected to activities within the environment [20].

The central point of the social cognitive theory within the context of teachers' practices and students' self-efficacy in the teaching and learning of Euclidean Geometry, may be described as a way of knowing what students know, as well as how and when they use such knowledge in the solving of Euclidean Geometry problems [27]. Teachers' reflection on their practice is not only a mere tool they use in Euclidean Geometry teaching; it is also a way of gathering and interpreting information during teaching with the aim to improve learning.
Teachers need to use alternative teaching approaches and learning strategies in Mathematics, especially Euclidean Geometry, as opposed to traditional teaching methods. This confirms what was reported in literature by [50].

Learning activities in Euclidean Geometry must stimulate students to employ their existing knowledge in constructing and deconstructing new information, as it will afford students the opportunity to develop a better understanding of Euclidean Geometry concepts. In this regard, teacher practices such as teaching, learning and assessment, are fostered to transform and meet the needs of students [51]. Furthermore, teachers could use van Hiele's Theory to stimulate students' cognitive skills, as it allows them to make sense of Euclidean Geometry concepts and apply their critical thinking skills when solving a Euclidean Geometry problem [52].

\subsection{Teacher Self-efficacy}

Self-efficacy, in this study, is defined in the geometry context as teachers' and students' judgements of their capability to organize and perform Geometry activities required to achieve the selected types of performances. Self-efficacy perceptions help determine what individuals do with the knowledge and skills they have [53]. It is believed, within the RTP\&SS-EG framework, that such teachers' and students' judgements, beliefs, and confidence, have the potential to enable them to perform Geometry tasks. It may be confirmed in this study that the teachers indeed also revealed the four components of self-efficacy, as identified by [30]. To utilize the RTP\&SS-EG framework, the components relating to teacher competency, engagement, flexibility as well as teacher competency relative to other teachers, are provided.

\subsubsection{Teacher competency}

Concerning teachers' competency, it is critical that teachers are competent in and knowledgeable about Euclidean Geometry concepts. It is important that teachers are motivated and have the self-confidence to teach the subject. It was found in this study that the teachers' positive feelings piqued self-confidence in the teaching of Euclidean Geometry. Teachers found the teaching of Euclidean Geometry to be easy, interesting, not boring, and they were good at it. Furthermore, teachers' competency could be stimulated by qualified teachers with specific subject content and pedagogical knowledge, teaching experience, preparing and planning Geometry lessons, and the use of relevant supporting material such as van Hiele's Theory to teach high school students Euclidean Geometry. All these qualities have the potential to furnish teachers with the necessary skills to be effective Mathematics teachers. It can be argued that these indicators of quality of teachers are essential and should receive special attention within the context of teaching 
and learning of Euclidean Geometry at the school level [21]. In addition, teacher competency could be improved by means of cognitive theory.

\subsubsection{Teacher engagement}

Teacher engagement is regarded as the extent to which the teacher's approach accommodates and promotes student engagement during the teaching and learning process [30]. Regarding teacher engagement, it may be argued that active teaching strategies have the ability to involve students during the teaching and learning process. Other teaching and learning strategies that may be used to foster engagement relate to group work, collaborative learning and problem-solving. These strategies, when applied in Geometry, encouraged students to be actively engaged. Problem-solving is helpful to students and assists in improving their mathematical abilities [54]. Another aspect that promotes teacher engagement is the incorporation of social constructivism theory, where students are actively engaged, and constantly constructing and reconstructing knowledge through environmental interactions [52]. Learning strategies and activities foster engagement, interaction, and participation among the students when teachers facilitate learning, and therefore, encouraged the student-centered approach [55]. These teaching and learning strategies increase creative and critical thinking, self-confidence, and self-efficacy during the teaching and learning of Euclidean Geometry [33].

\subsubsection{Teacher Flexibility}

Flexibility is described as a teacher who is able to display the ability to adopt various teaching strategies that may enhance Mathematics teaching [30]. It was critical for teachers to adjust their approach to teaching Euclidean Geometry when students encounter challenges in understanding the concepts. Teacher flexibility may be described as the fundamental feature within the constructivist strategies [56], as it encourages teachers to adopt the role of a facilitator [4]. We advise that teachers should be flexible in teaching by making use of various teaching and learning strategies related to question and answer, monitoring students individually, drill and practice, either in small groups, or in pairs.

Another aspect that should be used that have the potential to contribute towards promoting flexibility, is the development of learning materials that embraces cultural context [34]. As it was found in this study, some teachers make use of Geometry artefacts, meaning they make use of geometrical objects that surround them as a method to relate Geometry to real situations. The cultural context promotes the South African cultural indigenous, localization and Afrocentric knowledge in the Mathematics curriculum. Teachers should be flexible and incorporate such knowledge for the benefit of the students, allowing them to link the known to the abstract knowledge of Euclidean Geometry. Another important aspect of promoting flexibility in Mathematics and Euclidean Geometry teaching, is the value of parental involvement [57]. The aspects identified about Mathematics teachers being flexible, have the potential to promote high self-efficacy [58].

\subsubsection{Teacher Competency Relative to other Teachers}

Since the study was focused on Mathematics, the comparison was on Mathematics teacher practices on Euclidean Geometry within a high school context. It was found that, in comparison to other teachers, teachers in this study viewed themselves as very effective in their district. They regarded themselves to be competent in teaching Euclidean Geometry, as they promoted an active and flexible teaching approach. By using these teaching approaches, Mathematics teachers would be able to show the elements of the social cognitive theory of understanding students, and the subsequent application of gained knowledge to solve Geometry problems [59]. The study may also contribute to developing the culture of collaboration, and the sharing of best practices among mathematics teachers.

Another important aspect of teacher competency relative to other teachers is the mathematical disposition, which could serve as a predictor of self-efficacy for teaching Mathematics. As [37] argue, the teacher's prior Mathematics knowledge usually influence mathematical disposition and self-efficacy for teaching Mathematics, as it has a direct bearing on teachers' views of themselves relative to their peers [36].

In general, Euclidean Geometry is found to be a challenging part of Mathematics. In this case, teachers should acquire content knowledge and pedagogical content knowledge with adequate resources when planning the concept. In trying to overcome some of the problems, it is essential that teachers consult their colleagues for assistance, and collaborate to improve their competency in the presentation of Euclidean Geometry content knowledge. It is imperative that teachers develop the skills to integrate innovative teaching modes [60]. Since they are interconnected, effective Mathematics approaches that enhance Mathematics self-efficacy teaching are critical within the school environment.

\subsection{Student Self-efficacy}

The five components related to Student self-efficacy consist of competency, anxiety, comfort, interest, and the importance of Euclidean Geometry as discussed.

\subsubsection{Student competence}

Several factors that may be viewed as contributing to students' competency in Mathematics learning, include learning beliefs, enjoyment in the subject, a positive desire to help one another as well as to improve their Mathematics learning [38]. These competencies may also 
be attributed to the mastery of Geometry. Studies argue that students' knowledge, conceptions, views, and assumptions in Geometry affect their own learning [61]. The South African curriculum is based on the fundamental principles of constructivism, where the focus needs to be student-centered. However, the literature revealed that teachers misunderstood teaching-learning plans [62]. Teachers were observed using a series of activities meant for students to follow, and as a result, students had to adapt to the teachers' method of teaching [63]. In this case, it is argued that such a teaching approach may be misunderstood by the students, leading to ineffective learning strategies that might ultimately hinder the improvement of learning Geometry, where teacher-student involvement is critical [64].

From such a perspective, this implies that it is essential to explore student competency attributed to positive changes during Geometry learning. Research has established that self-efficacy beliefs, behavior changes and outcomes are highly correlated, and that self-efficacy is an excellent predictor of behavior [65]. Furthermore, the study shows that it is not simply a matter of how capable one is, but of how capable one believes oneself to be if a student is to succeed in understanding Geometry. The ability of teachers to believe in their capabilities is a unique form of competency that may need to be cultivated among students if they are to improve their Mathematics learning approach.

\subsubsection{Student anxiety}

Studies have shown that anxiety is an element that negatively affect the students' conceptual understanding of Geometry [8]. Furthermore, studies have illustrated that there are a variety of factors that may be associated with circumstances where anxiety prevails, consequently necessitating teachers to learn how to improvise in order to effectively teach Geometry $[8,9,39]$ and enhancing students' performance. Fear and apprehension are some of the key features associated with Geometry anxiety impacting on students' competence, hence the need for studies on how teachers' self-efficacy beliefs and students' achievement relate [11].

\subsubsection{Students' Comfort}

There are problem-solving approaches that are suggested to be innovative initiatives that may enhance self-confidence among students and promote comfort in learning [41]. The study was able to elaborate on how self-efficacy beliefs serve as a determining factor in how people think, feel, motivate themselves and behave. It observed that people form their own views and perceptions of their self-worth, their own capacity to accomplish goals, and how to overcome obstacles related to their learning of Euclidean Geometry.

Innovative approaches suggest that students' interpersonal intelligence may be promoted during
Euclidean Geometry learning, and this may enhance the feeling of being at ease during the teaching and learning process [41]. It is pivotal that student-teacher relationships are given special attention during Geometry lessons. Within the context of this study, it was noted that, when students think their teacher likes them, their participation and subject performance in Geometry may improve. This implies that students with a limited view on whether or not the teacher likes them, are likely to perform poorly in the subject [66].

It may be argued that students with positive perceptions about their relationship with teachers improve their belief and self-efficacy. Furthermore, teachers who provide a high level of emotional support, assist students to improve. In some instances, it is indicated that a self-regulated approach to problem-solving is required, particularly in Geometry [67]. Self-regulated learning is used as a tool during the phase when scaffolding has faded or removed once students have achieved the desired conceptual understanding of the learning process [66]. It is necessary for the teacher to ensure that students are comfortable in the learning environment.

\subsubsection{Student interest}

Interest is one critical factor viewed to play a pivotal role in enhancing students' self-efficacy in learning Geometry [10,30]. The study noted that students' engagement, homework frequency, and teacher flexibility are factors that positively influence students' interest in the subject, resulting in enhanced motivation to do well in the subject [48]. It may be argued that interest and motivation are closely related. It is then important to furthermore establish how they link and contribute to self-efficacy. High self-efficacy may affect motivation positively, or negatively. Despite interest being part of affection, it is perceived as a critical element of the learning process, yet it has not been given the attention it deserves in learning and teaching [68]. It may be argued that interest in the subject is one of the most commonly known affection constructs perceived as being essential in student learning and achievement in Geometry. Interest was found to be an appropriate indicator of problem-solving ability, and to a lesser degree, a student's prior experience with Geometry [68].

Students with high self-efficacy related to interest, are more likely to persist in a given task and may put in more efforts to complete such tasks, as opposed to students with low self-efficacy [69]. Self-efficacy is directly proportional to more active efforts. [48] link students' poor performance to the inability of a teacher in explaining concepts effectively, while those with a high self-efficacy will put more efforts into completing any given task. It may then be argued that it is critical for Geometry teachers to develop skills on how to form positive perceptions of Euclidean Geometry, since such students tend to become more involved in challenging 
activities in order to perform well. [6] argued that students' interest was observed through active involvement in Geometry lessons, whereby students engaged with teachers and asked questions when they did not understand. It was also found that peer-learning supported students in showing interest in the subject [10].

\subsubsection{The importance of Geometry to the student}

Students' perceptions of the importance of Geometry are regarded as a predictor of their success [30]. Within the context of the study, wherein the South African schools are mainly situated in disadvantaged communities, Mathematics is regarded highly by students. The study revealed that students perceived Geometry as part of Mathematics, which offers opportunities to gain access to Universities in Mathematical Sciences, Engineering, and other career paths [70]. The significance of Geometry is also related to the students' development of mental processes, which can be viewed as pivotal to enhance logical and critical thinking skills in problem-solving contributing to decision-making [4]. Such Geometry problem-solving activities are regarded as important in assisting students to understand the world in context, and also enhance inventiveness and original thinking [42]. The study highlights the prominence and significance of Geometry in our everyday happenings. Furthermore, the study provided insight on various aspects that students associate with the importance of Geometry in high school. The focus of the study was on the relationship between the teachers' practices and students' self-efficacy on the teaching and learning of Euclidean Geometry in high school.

\section{Limitation}

The limitation of RTP\&SS-EG framework is based on the fact that it was developed based on the findings from the participants from two provinces and two districts in South Africa. Another limitation is teachers' readiness, and exposure to Euclidean Geometry. Some of the teachers' lack of pedagogical content knowledge to teach Geometry had a noticeable, negative influence on their teaching. The Hawthorne effect restricted this study, wherein participants provide responses that they view as what a researcher may like. This aspect was further exacerbated by the fact that only open-ended questions were used in the qualitative aspects of the study, and no interviews were conducted.

\section{Conclusions}

In an attempt to combat South Africa's underperforming in Mathematics pedagogy, and to transform the perception of Mathematics being regarded as a difficult subject to teach and learn, the RTP\&SS-EG framework was developed. This framework contributed to the body of knowledge regarding the teaching and learning of Euclidean Geometry. The RTP\&SS-EG framework emphasizes that learning associated with the relationship between teachers' practices and students' self-efficacy, could be integrated in the everyday preparation of teaching-learning plans in Euclidean Geometry. It was emphasized that stakeholders such as policy makers, curriculum developers, subject experts, teachers, and students need to establish the relationship between teachers and students so as to improve the current practices of Mathematics, particularly the Euclidean Geometry concept at school. To better understand the teachers' practices and the students' relationship in Geometry, this study used self-efficacy instruments. It may be observed that factors such as competency, engagement, flexibility, and the teacher's competency relative to other teachers, assisted in understanding the relationship that should be asserted by teachers in order to make Geometry learning conducive. It may also be seen from the discussion that factors such as competency, anxiety, comfortability, interest, and the importance of Geometry to the student contributed to a better understanding of their relationship with teachers in Geometry. It was indicated in each of these factors how the theory of constructivism, social constructivism and social cognitivism played a major role in promoting teacher-student relationships in Geometry. New dimensions to the theory, and practice on the integration during the teaching and learning of Euclidean Geometry could be incorporated with the guidance of the RTP\&SS-EG framework. As Geometry is the foundation of engineering and technological development in teaching and learning, it should be approached with strategies proposed in this study.

\section{Recommendation}

It is recommended that the framework developed in this study and the contribution to the body of knowledge be adapted by policy makers, curriculum developers, subject experts, and teachers, and that it is to be utilized for best practice in Mathematics education to improve students' performance and alleviate the low pass rate in Mathematics. It is recommended that indigenous, localization and Afrocentric knowledge be included in the Mathematics curriculum, particularly in Geometry. This will assist and ensure that students learn the known from the unknown. It is recommended that further research be conducted on a similar phenomenon in other provinces in South Africa. It is critical that the instruments used in this study, GTS-EQ and GSS-EQ, be applied in other contexts such as in primary and secondary schools, to determine the consistency. It is also critical that a larger sample of 
teachers be considered in further research. A further study should be conducted to investigate the advantages and disadvantages of the RTP\&SS-EG framework.

\section{REFERENCES}

[1] Giannakopoulos, A, "An alternative way of solving geometry riders in grade 12: Back to synthesis and analysis," In 23rd Annual National Congress of the Association for Mathematics Education of South Africa, Port Elizabeth, South Africa, 2017.

[2] Department of Basic Education, DBE, "Revised National Curriculum Statement Grades R-9 (Schools) Mathematics. Gazette No. 23406, 443," Department of Education, Pretoria, 2002.

[3] Mahlobo, N., Mahlabela, P., Ndaba, T., "Teaching reasoning in Geometry through the GET phase to restore teachers' dignity in mathematics learning," In T. Penlington \& C. Chikiwa (Ed), Proceedings of the 23rd Annual National Congress of the Association for Mathematics Education of South Africa, South Africa, 2017.

[4] DBE, National Curriculum Statement (NCS): Curriculum and Assessment Policy Statement- Further Education and Training Phase (Grade 10 - 12) Mathematics, Department of Education, Pretoria, 2011.

[5] Ubah, I., "Pre-service mathematics teachers' semiotic transformation of similar triangles: Euclidean geometry,' International Journal of Mathematical Education in Science and Technology, pp. 1-22, 2021. DOI: 10.1080/0020739X.2020.1857858

[6] Mokoena, M. M, Simelane-Mnisi, S. Mji, A., Coetzer, L.M.J, "Exploring the effects of the use of interactive whiteboard on teachers' professional development in South African high schools," In M.P. Sebola, T Molokwane. Proceedings of the 4th Annual Conference on Democracy, Elections and Administration in Africa. South Africa: Johannesburg 2019, pp. 183 - 199.

[7] Teguh, A., Zaenuri, Z., Scolastika, M., "Analysis of Van Hiele's Geometry thinking ability in the 5e learning cycle model with ethnomathematics nuances in terms of student self-efficacy," Unnes Journal of Mathematics Education Research, vol. 11, no. 2, pp. 200-205, 2021. http://journal.unnes.ac.id/sju/index.php/ujmer

[8] Bikić, N., Maričić, S. M., M. Pikula, "The effects of differentiation of content in problem-solving in learning Geometry in secondary school," Eurasia Journal of Mathematics, Science \& Technology Education, vol. 12, no. 11, pp. 2783-2795, 2016. https://doi.org/10.12973/ eurasia.2016.02304a

[9] Ardasheva, Y. I. Carbonneau1, K. J. Roo, A. K., Z. Wang, "Relationships among prior learning, anxiety, self-efficacy, and science vocabulary learning of middle school students with varied English language proficiency," Learning and Individual Differences, vol. 61, pp. 21-30, 2018. https://doi.org/10.1016/j.lindif.2017.11.008

[10] Mamiala, D.P., Mji, A., S. Simelane-Mnisi, "Exploring students' anxiety about the learning understanding of
Geometry in high school", Proceedings of EDULEARN21 Conference July 5-6, 2021, 2021a, pp. 8051-8058.

[11] Mamiala, D.P., Mji, A., S. Simelane-Mnisi, "Students' interest in understanding geometry in South African high schools", Universal Journal of Educational Research, vol. 9 , no. $3, \quad$ pp. 487-496, 2021b. DOI: 10.13189/ujer.2021a.090308

[12] Mamiala, D.P. "Exploring the relationship between teachers' practices and students' self-efficacy in the teaching and learning of Euclidean Geometry at FET phase," Doctoral Thesis, Tshwane University of Technology: South Africa: Pretoria, 2020.

[13] Cowie, B. "Focusing on the classroom: Assessment for learning," In B. J. Fraser, K. G. Tobin, \& C. J. McRobbie (Eds.), Second International Handbook of Science Education (pp. 679-690, 2012). London: Springer.

[14] Xie, S., J. Cai. "Chinese Teachers' beliefs about mathematics teaching," In the 21 st century mathematics education in China (pp. 413-427, 2018). Springer, Berlin, Heidelberg. https://doi.org/10.1007/978-3-662-55781-5 20. (Accessed March 15, 2019).

[15] Lloyd, G.M. "Understanding elementary mathematics teacher education through the characteristics and activities of preservice teachers, elementary mathematics specialists, and mathematics teacher educators," Journal of Mathematics Teacher Education, vol. 2, no. 2, pp. 95-98, 2018. https://doi org /10.1007/s10857-018-9404-8

[16] Atebe, H.U., M. Schäfer. "The nature of Geometry instruction and observed learning-outcomes opportunities in Nigerian and South African high schools," African Journal of Research in Mathematics, Science and Technology Education, vol. 15, no. 2, pp. 191-204, 2011. https://doi.org/10.1080/10288457.2011.10740712

[17] L. Shidler. "The impact of time spent coaching for teacher efficacy on student achievement," Early Childhood Educational Journal, vol. 36, no. 2, pp. 453-460, 2009. https://doi.org/10.1080/10288457.2011.10740712

[18] Bruner, J. "Towards a theory of instruction," Cambridge, MA: Harvard University Press, 1966.

[19] Bandura, A. "Social foundations of thought and action," New York: Prentice-Hall, 1986.

[20] Swan, K. "A constructivist model for thinking about learning online," In J. Bourne, \& J. C. Moore (Eds.). Elements of quality online education: engaging communities. Needham: MA: Sloan-C, 2005.

[21] Reid-Martinez, K., L. D Grooms. "Online learning propelled by constructivism," In Encyclopaedia of Information Science and Technology, 4th ed, IGI Global, 2018, pp. 2588-2598.

[22] Taber, K. S. "Constructivism as educational theory: Contingency in learning, and optimally guided instruction," In J. Hassaskhah (Ed.), Education Theory, United Kingdom: NOVA Science Publisher, Inc, 2011, pp. 39-61.

[23] Alsup, J. "A comparison of constructivist and traditional instruction in mathematics," Educational Research Quarterly, vol. 28, no. 4, pp. 3-17, 2004. 
[24] Ektem, I. S. “A study on prospective teachers' self-efficacy beliefs regarding the implementation of constructivist approach: A case of Konya," Journal of Education and Training Studies, vol. 4, no. 3, pp. 118-125, 2016.

[25] Hendry, A., Hays, G., Challinor, K., D. Lynch. "Undertaking educational research following the introduction, implementation, evolution, and hybridization of constructivist instructional models in an Australian PBL high school," Interdisciplinary Journal of Problem-Based Learning, vol. 11, no. 2, 2017. https://doi.org/10.7771/1541-5015.1688

[26] Cetin-Dindar, A. "Student motivation in constructivist learning environment," Eurasia Journal of Mathematics, Science \& Technology Education, vol. 12, no. 2, pp. 33247, 2016. https://doi.org/10.12973/eurasia.2016.1399a

[27] Jamali, M., Zain, A. N., Samsudin, M. A., N. A. E. Ebrahim. "Self-efficacy, scientific reasoning, and learning achievement in the stem project-based learning literature," Journal of Nusantara Studies, vol. 2, no. 2, pp. 29-43, 2017. https://ssrn.com/abstract $=3101580$

[28] Mansour, N. "The experiences and personal religious beliefs of Egyptian science teachers as a framework for understanding the shaping and reshaping of their beliefs and practices about science-technology-society (STS)," International Journal of Science Education, vol. 30, no. 12, pp. 1605-1634,2008.https://doi.org/10.1080/09500690701 463303

[29] Pajares, F. "Self-efficacy beliefs and current directions in self-efficacy research." 2000. http://www.emory.edu/EDU CATION/ mfp/effpage.html (accessed March 15, 2019).

[30] Van der Bijl, J. J., L.M. "The theory and measurement of the self-efficacy construct," In E. A. Lentz \& L. M. Shortridge-Baggett (Eds.), Self-efficacy in nursing: Research and measurement perspectives, New York: Springer, 2002, pp. 9-28.

[31] Johnson C. W. The link between teacher practices and high school students' mathematics self-efficacy: A multilevel analysis. PhD Theses, Cleveland State University, 2008.

[32] Niss, M., Bruder, R., Planas, N., Turner, R., J. Villa-Ochoa. "Conceptualisation of the role of competencies, knowing and knowledge in mathematics education research," ZDM: Mathematics Education, vol. 48, no. 5, pp. 611-632, 2016. DOI 10.1007/978-3-319-62597-3

[33] Laurens, T., Batlolona, F. A., Batlolona, J. R., M. Leasa. "How does realistic mathematics education (RME) improve students' mathematics cognitive achievement?" Eurasia Journal of Mathematics, Science and Technology Education, vol. 14, no. 2, pp. 569-578, 2018. https://doi.org/10.12973/ejmste/76959

[34] Ulandari, L., Amry, Z., S. Saragih. "Development of learning materials based on realistic mathematics education approach to improve students' mathematical problem-solving ability and self-efficacy," International Electronic Journal of Mathematics Education, vol. 14, no. 2, pp. 375-383, 2019.

[35] Peranginang, S. A., Saragih, S., P. Siagian. "Development of learning materials through PBL with Karo culture context to improve students' problem-solving ability and self-efficacy," International electronic journal of mathematics education, vol. 14, no. 2, pp. 265-274, 2019. https://doi.org/10.29333/iejme/5713

[36] Saragih, S., Napitupulu, E., M. Fauzi. "Developing learning model based on local culture and instrument for mathematical higher order thinking ability," International Education Studies, vol. 10, no. 6, pp. 114-122, 2017. https://doi.org/10.5539/ies.v10n6p114

[37] Cobanoglu, R., Capa-Aydin, Y., A. Yildirim. "Sources of teacher beliefs about developmentally appropriate practice: A structural equation model of the role of teacher efficacy beliefs," European Early Childhood Education Research Journal, vol. 27, no. 2, pp. 195-207, 2019. https://doi.org/10.1080/1350293X.2019.1579547

[38] Cruz, J. M., Wilson, A. T., X. Wang. “Connections between pre-service teachers' mathematical dispositions and self-efficacy for teaching mathematics," International Journal of Research in Education and Science (IJRES), vol. 5, no. 2, pp. 400-420, 2019.

[39] Ramirez, G., Hooper, S. Y., Kersting, N. B., Ferguson, R., D. Yeager. "Teacher math anxiety relates to adolescent students' math achievement," AERA Open, vol. 4, no. 1, pp. 1-13, 2018. https://doi.org/10.1177/2332858418756052

[40] Chen, C.L., P. Herbst. "The interplay among gestures, discourse, and diagrams in students' geometrical reasoning," Educational Studies in Mathematics, vol. 83, no. 2, pp. 285307, 2019. https://doi.org/10.1007/s10649-012-9454-2

[41] Segumpan, L.L.B., D.A. Tani. "Mathematics performance and anxiety of junior high school students in a flipped class," European Journal of Education Studies, vol. 4, no. 12, pp. 1-33, 2018. http://dx.doi.org/10.46827/ejes.v0i0.1841

[42] Zakeri, A., Rahmany, R., E. Labone. "Teachers' self-efficacy and collective: The case of novice English language teachers," Journal of Language Teaching and Research, vol. 7, no. 1, pp.158- 67, 2016. DOI: 10.17507/JLTR.0701.18

[43] Kinavai, E., F. Biddulph. "Community mathematics. Teachers and curriculum," 2017. www.tandc.ac.nz (accessed March 15, 2019)

[44] Cicchetti, D. V. "Guidelines, criteria, and rules of thumb for evaluating normed and standardized assessment instruments in psychology," Psychological Assessment, vol. 6, no.4, pp. 284-290, 19194. https://doi.org/10.1037/10403590.6.4.284

[45] Onwuegbuzie, A. J., K.M.A. Collins. "Typology of mixed methods sampling designs in social science research," The Qualitative Report, vol. 12, no. 2, pp. 281-316, 2007.

[46] Ding, L., Jones, K., D. Zhang. "Teaching geometrical theorems in grade 8 using the 'Shen Tou' method: A case study in Shanghai,” In: L. Fan, N. Y. Wong, J. Cai \& S. Li. (Eds.), How Chinese teach mathematics: Perspectives from insiders, Singapore: World Scientific, 2015, pp. 279-312.

[47] Schunk, D. H., F. Pajares. "Self-efficacy beliefs," In P. Peterson, E. L. Baker \& B. McGaw (Eds.). International encyclopaedia of education, 3rd ed, New York: Elsevier Ltd., 2010, pp. 668-672.

[48] Kunter, M., Klusmann, U., Baumert, J., Richter, D., Voss, T., A. Hachfeld. "Professional competence of teachers: Effects on instructional quality and student development," 
Journal of Educational Psychology, vol. 105, pp. 805-820 2013. https://doi.org/10.1037/a0032583

[49] Hodgson, C., K. Pyle. "A literature review of assessment for learning in science," National Foundation for Educational Research, 2010. http://doi=10.1.1.471.3251

[50] Machisi, E. "Grade 11 students' reflections on their Euclidean Geometry learning experiences," EURASIA Journal of Mathematics, Science and Technology Education, 2021, vol. 17, no.2, pp. 1-19, 2021. https://doi.org/10.29333/ejmste/9672

[51] Liu, S. H. J., Y.J. Lan. "Social constructivist approach to web-based EFL learning: Collaboration, motivation, and perception on the use of Google docs," Educational Technology \& Society, vol. 19, no. 1, pp. 171-186, 2016.

[52] Mosoge, M. J., Challens, B. H., M.I. Xaba. "Perceived collective teacher efficacy in low performing school," South African Journal of Education, vol. 38, no. 2, pp. 1-9, 2018. DOI: $10.15700 /$ saje.v38n2a1153

[53] Ngirishi, H. "Exploration of FET mathematics learners' and understanding of Geometry," Masters' Thesis, University of KwaZulu Natal, Durban, 2015.

[54] Pajares, F. "The development of academic self-efficacy," In A. Wigfield \& J. Eccles (Eds). Development of achievement motivation, San Diego: Academic Press, 2002, pp. 16-31.

[55] Gür, H., M. Kobak-Demir. "Geometry teaching via origami: The views of secondary mathematics teacher trainees," Journal of Education and Practice, vol. 8, no. 15, pp. 65-71, 2017.

[56] Mnisi, S. "Exploring a teaching strategy using clicker mobile technology for active learning in undergraduate mathematics classes," Doctoral Thesis, Tshwane University of Technology: 2015, South Africa: Pretoria.

[57] Gresham, G., T., T Shannon. "Building mathematics discourse in students," Teaching Children Mathematics, vol. 23 , no. 6 , pp. $360-366,2017$. https://doi.org/10.5951/teacc hilmath.23.6.0360

[58] Sapta, A., Hamid, A., E. Syahputra. "Assistance of parents in the learning at home," Journal of Physics: Conference Series, vol. 11, no. 14, 2018. doi: 10.1088/1742-6596/1114/1/012143

[59] Ammamiarihta, E., Syahputra, E., E Surya. "Development of learning devices-oriented problem-based learning to increase student's combinatorial thinking in mathematical problem-solving ability," Paper presented at the 2nd Annual International Seminar on Transformative Education and Educational Leadership, Advances in Social Science Education and Humanities Research, 2017. https://doi.org/10.2991/aisteel-17.2017.71
[60] Dysthe, O. "The challenge of assessment in a new learning culture," In A. Havnes, \& L. McDowell (Eds.), Balancing dilemmas in assessment and learning in contemporary education, New York: Routledge, 2008, pp. 15-28.

[61] Selden A., Selden J., A. Benkhalti. "Proof frameworks: A way to get started," Primus, vol. 28, no. 1, pp. 31-45, 2018. https://doi.org/10.1080/10511970.2017.1355858

[62] Pfitzner-Eden, F., Thiel, F., J. Horsley. "An adapted measure of teacher self-efficacy for preservice teachers: Exploring its validity across two countries," Zeitschrift für P€adagogische Psychologie, vol. 28, no. 3, pp. 83-92, 2014. https://doi.org/10.1024/1010-0652/a000125

[63] Mkhize D. R. "Forming positive identities to enhance mathematics learning among adolescents universal," Journal of Educational Research, vol. 5, no. 2, pp. 175-180, 2017.

[64] Spaull, N. "South Africa's education crisis: The quality of education in South Africa 1994 - 2011," Report Commissioned by Centre for Development and Enterprise 2013, South Africa.

[65] Peng, P., Namkung, J., Barnes, M., C. Sun. "A meta-analysis of mathematics and working memory: Moderating effects of working memory domain, type of mathematics skill, and sample characteristics," Journal of Educational Psychology, vol. 108, no. 4, pp. 455-473, 2016. https://doi.org/10.1037/edu0000079

[66] Prewett, S. L., Bergin, D. A., F. L. Huang. "Student and teacher perceptions on student-teacher relationship quality: A middle school perspective," School Psychology International, vol. 40, no, 1, pp. 66-87, 2019. https://doi.org/10.1177/0143034318807743

[67] Jaakkola, T., K. Veermans. "Exploring the effects of concreteness fading across grades in elementary school science education," Instructional Science. Advance Online Publication, vol. 46, no. 2, pp. 185-207, 2018. https://doi.org/10.1007/s11251-017-9428-y

[68] Schukajlow, S., Rakoczy, K., R. Pekrun. "Emotions and motivation in mathematics education: Theoretical considerations and empirical contributions," ZDM Mathematics Education, vol. 49, no. 3, pp. 307-322, 2017. https://doi.org/10.1007/s11858-017-0864-6

[69] Tsao, Y. L. "The effect of constructivist instructional-based mathematics course on the attitude toward Geometry of pre-service," US-China Education Review A, vol. 1, no. 8, pp. 1 -10, 2018. DOI: 10.17265/2161-623X/2018.01.001

[70] Choudhary, A., Naresh, T., Shubhanshu, M. "Importance of mathematics and Geometry in architecture," Journal of Recent Activities in Architectural Sciences, vol. 1, no.1, pp. $1-11,2016$ 